This item was submitted to Loughborough's Research Repository by the author.

Items in Figshare are protected by copyright, with all rights reserved, unless otherwise indicated.

\title{
The relevance of taboo language: an analysis of the indexical values of swearwords
}

PLEASE CITE THE PUBLISHED VERSION

http://dx.doi.org/10.1016/j.pragma.2013.06.009

PUBLISHER

(C) Elsevier

VERSION

VoR (Version of Record)

\section{PUBLISHER STATEMENT}

This work is made available according to the conditions of the Creative Commons Attribution-NonCommercialNoDerivatives 4.0 International (CC BY-NC-ND 4.0) licence. Full details of this licence are available at: https://creativecommons.org/licenses/by-nc-nd/4.0/

\section{LICENCE}

CC BY-NC-ND 4.0

\section{REPOSITORY RECORD}

Christie, Chris. 2019. "The Relevance of Taboo Language: An Analysis of the Indexical Values of Swearwords". figshare. https://hdl.handle.net/2134/18930. 
The relevance of taboo language: an analysis of the indexical values of swearwords.

\section{$1 \quad$ INTRODUCTION}

The assumption that the use of a particular word or linguistic resource can produce (im)politeness effects in some contexts, but not in all, is uncontroversial. For example, scholarship that addresses swearing as (im)politeness behaviour has repeatedly shown that, as a resource, taboo language can be used to generate a number of communicative effects in different contexts (see, for example, Brown and Levinson, 1987; Daly et al., 2004; Rogerson-Revel, 2007; Jay and Janschewitz, 2008; Stenstrom, 2006; Dewaele, 2010; Johnson, 2012). However context, as a concept that can explain variation in the effects generated by a single linguistic resource, is often under-theorised, even when apparently well-theorised phenomena, such as 'communities of practice', are invoked as context. My contention in this paper is that, in particular, the processes by which key aspects of context come to have a bearing on specific evaluations of a linguistic resource are often left underexamined. My aim in this paper is to develop a discursive pragmatic approach to (im)politeness phenomena, that draws on recent developments in the theorisation of indexicality, and which raises questions about the processes that generate context-specific evaluations of swearword use. From a politeness perspective, this approach is useful for the analysis of any linguistic resource, but my aim here is to propose that such an approach allows questions about the scope, the power, and the workings of the indexical potential of strong swearwords to be formulated and addressed.

In this paper I take a 'discursive approach' to (im)politeness to be an approach that roughly maps onto Culpeper's (2011:122) account: it is an approach that is concerned with "participants' situated and dynamic evaluations of politeness". However, as I hope to show, adopting such an approach does not necessarily generate the problems that Culpeper (122) 
points to. I hope to demonstrate that the questioning of generalisations, which characterises discursive approaches, does not (as the scholarship cited by Culpeper argues) necessarily lead to an inability to go beyond the descriptive, and does not necessarily lead to the redundancy of the analyst. In what follows I take (im)politeness phenomena to be communicative resources that can be shown to be subject to politeness evaluations (whether these are etic or emic; first order or second order evaluations). The discursive approach to (im)politeness I develop in this paper takes as a point of departure some of the insights brought into view by the 'third wave' approach to sociolinguistic phenomena (Eckert, 2012)i. I propose that, by adopting this approach, it is possible to map out the indexical potential of specific linguistic resources, such as swearwords by addressing the processes by which "meanings become associated with social categories or with variables" (Eckert, 2008:455). I extend the sociolinguistic approach to indexicality by adding a pragmatic dimension, informed by key tenets of Sperber and Wilsons (1986) relevance theory. My aim in doing so is to propose that such a methodology would bring into view factors that inform the social meanings that communities appear to attribute to linguistic resources, and also help to explain individual attributions of social meaning to specific uses of linguistic resources, without addressing such meanings as nonce interpretations, or as affirmations or rejections of the 'conventionalised' meanings attributed to such resources. I conclude with an analysis that is designed to show how it might be possible to move beyond speculation about what a resource does or does not signify within a given culture at a given moment. In pointing to regularities of situated evaluative behaviour, that can be observed and documented, my goal is also to provide a set of parameters for inferring the meanings generated by local, context-specific uses of swearwords. 
McEnery $(2006,2)$ explicitly links swearing with offence, but also posits a context within which an offence would occur, arguing that the term 'bad language' in his work refers to "any word or phrase which, when used in what one might call polite conversation, is likely to cause offence". McEnery does not engage with the concept of 'polite conversation' in any depth, but his claim is consistent with other academic treatments of swearing. For example, Allan and Burridge (2006:2), who term swearwords as 'dysphemisms' (in contrast with 'euphemisms'), propose:

In order to be polite to a casual acquaintance of the opposite sex, in a formal situation, in a middle class environment, one would normally be expected to use the euphemism or orthophemism rather than the dispreferred counterpart. The dispreferred counterpart would be a dysphemism. (34-5).

Although both the above works relate offence to context, in what follows I focus primarily on two swearwords, fuck and cunt, because these have been described in the literature as amongst the most strongly offensive swearwords in British English in any context (see, for example, Millwood-Hargreave, 2000:9-10; McEnery, 2006:35; Stone et al., 2010:53). The offensiveness of these terms is often perceived as a function of their 'taboo' status (Allan and Burridge, 2006; McEnery, 2006). As Stapleton (2010:289) argues: "Swearing is a linguistic practice based on taboo, or that which is forbidden". Although there is clearly a link between the offence caused by a swearword and its taboo status, as I show in Section 2, studies of (im)politeness behaviour that analyse instances of the context-specific meanings of swearword use tend to support the less theorised claims cited above.

In Section 3 I survey sociolinguistic and anthropological scholarship on indexicality with the aim of demonstrating how this approach has the potential to open up a useful set of research questions that might add an explanatory layer to the analysis of swearword use. In Section 4, I demonstrate how a discursive pragmatic approach that builds on the notion of 
indexicality can be used to describe and explain the indexical potential of items of taboo language.

\section{SWEARING IN POLITENESS RESEARCH}

I have proposed above that scholarship in the field of politeness has shown that the interactional effects of swearwords are context-dependent. In this section, I provide a brief illustration of how such studies have supported these claims, focusing on just two: Culpeper, Bousfield and Wichmann (2003), who have shown that, where the intention is to cause offence, the use of a swearword can function as an impoliteness strategy; and Daly et al. (2004) who have shown that swearing can also express solidarity when it functions as a positive politeness strategy. I conclude this section with a brief summary of Culpeper's (2011) argument that the meanings associated with swearwords are conventionalised, rather than conventional, (see section 2.2) and his proposal that this accounts for the range of context-specific effects they are able to generate.

\subsection{Swearing as an impoliteness strategy and a positive politeness strategy}

Culpeper, Bousfield and Wichmann's (2003:1550) analysis of the following exchange illustrates how swearing can function as an impoliteness strategy. In what follows S1 is a traffic warden and S2 owns a car that has just received a parking penalty.

S1:

I'm afraid I have sir=

S2: you have no authority to put a ticket on a disabled err car $=$ why didn't you

S1: $\quad$ l'd . what do you mean I did do it before

S2: do it before then

I've parked here every day because I have a

S1:

yes sir

I never really

S2: prescription from the chemist you don't put any tickets on my car and then and 
The italics are in the original, and signal the element of the exchange that the authors are focusing on at this point. The argument here is that a key criterion for distinguishing between politeness and impoliteness is the aim of the speaker, specifically "whether it is the speaker's intention to support face (politeness) or to attack it (impoliteness)" (2003:1550). The authors argue that the above exchange "contains an offence which aims at aggravating the face of the intended recipient" (1550) and is an example where an offending person is acting "with the intention of causing open insult" (1550). In proposing that the italicised element, i.e. the words 'ohh fuck', is 'an offence' in this exchange, Culpeper et al. illustrate how this swearword can function as an impoliteness resource.

There is also evidence in the literature that swearwords can function as a politeness resource. For example, Daly et al. (2004) offer evidence of an alternative effect generated by the use of fuck, arguing that in some contexts its use can express solidarity. This claim is supported by an appeal to community of practice norms. The following is an extract from a conversation that takes place in a New Zealand factory between two men who work on a packing line putting soap powder into boxes: Russell and Lesia. Lesia has responsibility for the planning of work-shifts. The material in brackets indicates the elements of the turn that were difficult to transcribe because machine noise is affecting the audibility of the interaction.

Russell: $\quad$ fucking sick of this line (Lesia)

Lesia: [voc]

Russell: $\quad$ stuck here all the time

Lesia: if you I put you on that line you're getting worse

Russell: ( )

Lesia: $\quad$ fucking worse + slow like an old man (all you have to just) + + 
$\begin{array}{ll}\text { Russell: } & \text { that's what I want }+++ \\ \text { Lesia: } & \text { if I put on that line you falling asleep (6) } \\ \text { Russell: } & \text { how much do we have to do on here }\end{array}$

(Daly et al., 2004:952)

The authors gloss the content of this exchange in the following way:

Russell is complaining that he is fed up with being on this packing line ...while Lesia argues back that any other line would be worse because Russell would find it too slow and boring. (952)

Daley et al. argue that if, drawing on Brown and Levinson's theory of politeness, Russell's direct complaint in line one was classified as a face threatening act, it would be expected that the speaker "would use some kind of linguistic politeness strategy to attenuate the impact of his complaint" (952). However, as the authors point out, Russell does not do this, but instead uses the word fucking "thus apparently boosting or intensifying the insult value of his FTA" (952). They argue that to interpret the socio-pragmatic meaning of the utterances in their data it is necessary to draw on wider ethnographic information as well as to consider other examples of complaints by the community of workers they are studying. On this evidence, the authors (952) propose the following explanation of Russell's behaviour: These men are on such good terms that they can swear at each other, not only with impunity, but with positive affect. Forms of fuck appear to act as markers of solidarity and positive politeness for members of this community of practice.

As both the above studies show, the effect of the lexeme fuck is dependent upon the way it is evaluated within a specific context. However, as I have suggested elsewhere (Christie, 2005:5-6), such claims tend to be predicated on the assumption that there is an already-existing shared understanding that such swearwords are normally face threatening. Daly et al. (2004:960) explicitly state this when they conclude: 
The inherent strength of the canonical expletive fuck thus contributes to its impact when used between friends and co-workers. It is as if they are saying "I know you so well I can be this rude to you."

And although Culpeper et al. (2003) do not explicitly state that the expletive fuck has an inherent pragmatic force, in proposing that the utterance they are analysing contains "an offence which aims at aggravating the face of the intended recipient" (2003:1550), and since the italicised element of their data is the word fuck, in this instance they are treating the word fuck as 'an offence'. Although the authors are not proposing that the word always functions in this way it would appear that, unless there is a reason to justify an alternative interpretation, the evaluative process does not need to be made explicit. A sort of 'out of context' (Culpeper, 2011:124) evaluation holds.

\subsection{Conventionalised meanings of swearwords}

The complexity of explaining the effects of swearing within (im)politeness research is nicely illustrated by Culpeper's (2011) account of a personal experience related by one of his informants. The informant, a young British man, tells of how he and his parents were having a meal with the informant's Norwegian friend, and of how the friend repeatedly used the word cunt when telling anecdotes (in English) about mutual friends. The informant observes:

I knew Eddie uses this word in the place of words like 'guy' and 'dude'. In our circle of friends "Hi cunt" was a friendly greeting. However, my parents weren't to know this.... (Culpeper, 2011:116)

The informant goes on to add that he "wanted everyone to get along, but difference in their language use was causing offence" (2011:116). As Culpeper argues, it is likely that the parents would have perceived the use of the word as misjudged and, although they may 
have been somewhat offended, the offence is unlikely to have been "exacerbated by a construal of intentionality". He adds that the offence is likely to have been "mitigated by an understanding that it is miscommunication" (2011:116). What is interesting about this example of swearword use is that it shows what happens when there appear to be two or more sets of value systems involved in the interpretation of a linguistic resource. For the informant, it would appear that the word has the potential to be relatively neutral in its effects in certain contexts, and this is explained by his experience of its use as part of "a friendly greeting".

Culpeper's account here acknowledges the instability of meanings emphasised by discursive approaches to politeness, but takes issue with aspects of the discursive stance. He proposes that the repeated appeals to context proposed by such approaches, which "challenge old modules of communication", tend to "give the erroneous impression that it does not matter what you say" (116). And he describes discursive approaches to politeness in the following terms:

discursive studies downplay, partly for rhetorical reasons, shared conventions of meaning, instead emphasising that meanings are very unstable, negotiable and fuzzy and that communication is a very uncertain business. (2011:123)

Instead, Culpeper makes a case for how evaluations of uses of impoliteness formulae such as swearwords tend to be relatively stable because they are constrained by the conventionalised associations that interlocutors share. He argues that this is evident from: the commonplace fact that people have opinions about how different expressions relate to different degrees of politeness or impoliteness out of context, and often opinions which are similar to others sharing their communities. They must have some kind of semantic knowledge; or to put it another way, the pragmatics of these expressions must be semantically encoded in some way. (2011:124) 
Drawing on Terkourafi (2008), Culpeper makes the point that this semantic knowledge is 'schematic knowledge' in that it relates to conventionalised (rather than conventional) meanings, that is to say, such meanings are arrived at through a process in which "particular expressions are associated in one's mind with particular contexts" (129).

Culpeper refines his own position on the significance of context by distinguishing it from that of Tracy and Tracy, who make a distinction between 'context-spanning strategies' and 'context-tied strategies': the former are impoliteness strategies that have the same effect across different situations of use, and the latter are strategies that can be "neutralised or even face enhancing" in certain contexts of use (Tracy and Tracy cited in Culpeper, 2011:117). Culpeper rejects an earlier opinion he had held, that certain forms of taboo language can be context-spanning strategies (116), and his point in citing his informant's experience is to illustrate how the effects of "negative behaviours/formulae" (116) are depend on context of use. However he does not propose a 'discursive' explanation of this context-dependency. Indeed he maintains that the effects of some linguistic formulae, including the saying of certain swearwords using specific intonational contours, are sufficiently "conventionalised" to be seen as impolite in any context:

Consider, for example, cunt dropped into the frame of you $\mathrm{X}$, delivered with a sharply falling intonation and stress on cunt, and an expression of disgust. I would suggest that this is unlikely to be taken as neutral in many different situations. (2011:117)

As Culpeper points out, this does not mean that a conventionalised expression of (im)politeness will always be interpreted as (im)polite. The example of the Norwegian speaker indicates that such an interpretation can always be cancelled in context (129):

Whilst impoliteness formulae can be highly conventionalised, it is not so clear, in my view, that generally they can ever be as fully conventional as non-politeness concepts, such as land, water, sky, etc. For example, cunt was generally viewed as 
the most offensive word in British English in the year 2000 (Millwood-Hargreave 2000). But we saw an example [...] in which it was not used for impoliteness. (127)

This position is a useful starting point, but it raises many questions about the process by which such evaluations are ascribed to linguistic resources.

In arguing, for example, that the meanings of linguistic resources are arrived at through a process in which "particular expressions are associated in one's mind with particular contexts" (129), one question that remains unanswered is how are these associations generated? And for whom are these associations generated? To pre-empt a set of questions asked by Agha (2003:242) which I will address further in section 2.2 below: what is involved in claiming that such cultural evaluations exist at all? And for whom do they exist? I propose that in order to address questions about cultural evaluations of (im)politeness resources, such as swearwords, we need to look to both sociolinguistics and pragmatics. In the remainder of this paper I ask what, precisely, are we assuming about the social and cultural context of language use and language users when we attempt to account for evaluations of strong swearwords? I also ask how, in pragmatic terms, we can account for the processes that lead swearwords to trigger one evaluation in one context and a different evaluation in another. Although my approach is discursive, I do not assume that because language users may evaluate swearwords differently to each other, that it does not matter what we say, or that the analyst is redundant. And neither do I propose that communication is, for the most part, an 'uncertain business'.

In addressing the questions I have posed, I build on recent developments in the theory of indexicality. I argue in particular that although the notion of indexicality is essentially pragmatic, in recent years it has been employed as a sociolinguistic concept. My 
aim is to show that if the pragmatic roots of indexicality are brought back into play, it raises interesting questions about the role of context in the evaluation of (im)politeness resources.

\section{$3 \quad$ INDEXICALITY}

Ochs glosses indexing in the following terms:

To index is to point to the presence of some entity in the immediate situation at hand. In language, an index is considered to be a linguistic form that performs this function. [...] A linguistic index is usually a structure (e.g. sentential voice, emphatic stress, diminutive affix) that is used variably from one situation to another and becomes conventionally associated with particular situational dimensions such that when that structure is used, the form invokes those situational dimensions (Ochs, 1996:411).

She theorises this ability to assign meanings to linguistic resources as a form of cultural competence that a novice, for example a child or a newcomer to a culture, accrues in the process of becoming a member of the world s/he is entering. Ochs argues for an 'indexicality principle', which she describes as the tenet that:

[S]ocialisation is in part a process of assigning situational, i.e. indexical, meanings (temporal, spatial, social identity, social act, social activity, affective or epistemic meanings) to particular linguistic forms. (1996:410)

This is a particularly useful starting point for politeness scholars because her model theorises the act of assigning social meaning to a linguistic form as a pragmatic process, and the model is therefore designed to address the link between the social and the pragmatic, as well as the global and the local, which is precisely what politeness theories attempt to do.

\subsection{The Indexicality Principle (Ochs, 1996)}

In particular Ochs' work highlights the need for a pragmatic account of the linguistic indexing of social identity. She proposes that aspects of social identity are constructed on the basis 
of inferred acts and attitudes signalled through the use of specific linguistic forms. The distinctions between aspects of social identity that Ochs makes are worth recalling:

Social identity encompasses all dimensions of social personae, including roles (e.g. speaker, overhearer, master of ceremonies, doctor, teacher, coach), relationships (e.g. kinship, occupational, friendship, recreational relations), group identity (e.g. gender, generation, class, ethnic, religious, educational group membership), and rank (e.g. titled and untitled persons, employer and employee), among other properties. (1996:410)

A key insight that derives from these distinctions is Ochs' frequently quoted observation that "few features of language directly and exclusively index gender" (341). Her analyses of talk show that group identity such as 'gender' is likely to be inferred on the basis of the indexing of roles, which are in turn inferred on the basis of indexed stances and acts.

In illustrating the pragmatic processes by which aspects of social identity are inferred, Ochs argues, for example, that a role such as 'doctor' is likely to be inferred on the basis of stance: "one might display the stances of knowledgeability, objectivity and care to build a certain kind of medical professional identity" (424). Stances and acts are defined as follows:

Social act refers to a socially recognized goal-directed behaviour, e.g. a request, an offer, a compliment.

affective stance refers to a mood, attitude, feeling, and disposition, as well as degrees of emotional intensity vis-à-vis some focus of concern.

epistemic stance refers to knowledge of belief vis-à-vis some focus of concern, including degrees of certainty of knowledge, degrees of commitment to truth of propositions, and sources of knowledge, among other epistemic qualities. (Ochs, 1996:410)

It is important to recall that Ochs does not assume that the link between a linguistic structure and a social meaning such as an act or a stance is in any way fixed. She argues, for example, that: 
Interlocutors may use these structures to index a particular identity, affect, or other situational meaning; however, others co-present may not necessarily assign the same meaning (Ochs 1996:413).

Ochs' position here is consistent with that of current approaches to the study of politeness: no analyst today would want to propose that a specific linguistic resource such as the use of the word sorry always indexes a social act such as 'an apology', or that the use of the word fuck invariably indexes 'an oppositional stance'. Indeed it would not be difficult to imagine contexts when the use of the word fuck could index an apology and a use of the word sorry could index an oppositional stance. And as a brief glance through any edition of the Journal of Politeness Research or this journal will show, much of the current politeness research that focuses on communities of practice and activity types brings into view just how wide a range of meanings a particular resource or linguistic variable can have. However, I would argue that such research is still to provide a sufficiently descriptive and explanatory account of how specific social meanings come into existence, what specific meanings a resource can index, or how context plays a part in the selection of one meaning rather than another.

Eckert's (2008) work on indexicality and sociolinguistic variation goes some way to accounting for the way in which linguistic resources come to acquire social meanings. Although she does not directly cite Ochs' work on indexicality (and this possibly accounts for the loss of the pragmatic element in the sociolinguistic adaptation of the indexicality principle) what Eckert and Ochs share is a focus on the instability of social meaning, and in particular a focus on the role of ideology in the generation and perpetuation of social meanings. For example, in questioning the meanings assigned to variables in early variationist studies, such as Labov's claim that the use of centralized /ay/ signals local 
authenticity within a particular speech community, Eckert argues that "the meanings of variables are not precise or fixed but rather constitute a field of potential meanings" (2008:454). She refers to the field of potential meanings that variables can have as an 'indexical field', and describes this as a "constellation of ideologically related meanings, any one of which can be activated in the situated use of the variable" (2008:454). In developing this account, Eckert draws on Agha's (2003) concept of 'enregisterment' and Silverstein's (2003) account of the 'indexical order'. The sociolinguistic adoption of this approach has already begun to generate a steadily expanding literature. See, for example, Anderson (2008); Cole (2010); Snell (2010) and Squires (2010). Before addressing the usefulness of Eckert's notion of the indexical field for the analysis of swearword use, it is worth considering the concepts of 'enregisterment' and the 'indexical order' in more depth as they have a particular relevance for the development of a systematic approach that can address the range of effects that situated uses of swearwords can generate.

\subsection{Enregisterment (Agha, 2003)}

Agha's (2003) account of enregisterment traces the process by which Received Pronunciation as a class accent within British English has achieved, and retained, a particular prestige. He shows how, since the eighteenth century, commentaries found in a wide range of sources, including books, novels, newspapers and television programmes have generated a metadiscourse of RP that has created and continued to reproduce the cultural values ascribed to this accent. Although the accent itself, as well as the specifics of the metadiscourse surrounding the accent, have changed over the centuries, Agha shows that, within this metadiscourse, RP continues to be associated with personal qualities such as having refined manners, good breeding, good education, rationality, etc. Agha uses the term 'enregisterment' to refer to the process by which the features of the accent have come 
to be associated with specific qualities and in doing so have become available as a signalling device. From Agha's perspective, if a non-native speaker of RP elects to use features of RP in a context in which heii is attempting to signal the above personal qualities, he would be attempting to align his social identity with that which he ascribes to an RP speaker. But just as significantly he would potentially be endorsing and perpetuating the link between intelligence and education and the use of RP. And, of course, this is also to actively subscribe to a highly ideological stance that is promulgated by this specific metadiscourse of RP.

A key feature of Agha's argument is that any metapragmatic activity is ideological because it is a situated activity: it has a speaker or writer, who has a particular identity and a particular set of goals. Moreover, any metapragmatic act involves speech or writing that is located within a specific medium, which has its own set of goals and its own conventions. So, for Agha, to talk about the cultural value ascribed to a register is not to talk about an abstract phenomenon. He argues that value ascriptions can be located in discourses that take place in the public sphere and in individual response, and asks "But what is involved in claiming that such cultural values exist at all? For whom do they exist?" (2003:242) and in responding to those questions comments:

In speaking of 'cultural values' I wish to invite no metaphysics of shared belief. To say that pragmatic behaviours - such as uses of a register-have cultural values associated with them is simply to say that certain regularities of evaluative behaviour can be observed and documented as data. Indeed, all of the evidence for register values presented above consists of data of observable metapragmatic activity. ..Yet all such behaviour is unavoidably positioned, by its very nature, as the activity of socially locatable persons. (2003:242)

There is insufficient space here to address Agha's claims in detail, but his work is a useful extension of Ochs' theorisation of social identity as a function of indexicality in that he 
argues that the metapragmatic activity that is evident in cultural texts draws on and perpetuates 'metapragmatic stereotypes' which he argues are "identifiable for a particular social domain of evaluators, e.g. a particular sub-population within a society" (242). Therefore, cultural values are not intrinsic to a register, but are the function of acts of interpretation carried out by socially situated evaluators.

This is significant because, in common with Ochs, Agha does not assume that metapragmatic evaluations will be consistent with each other within a given society, and instead argues that "their mutual inconsistency" often provides "crucial evidence for the coexistence of distinct, socially positioned ideologies of language within a language community". Agha links these ideologies with the linguistic indexing of social identity by proposing that:

metapragmatic representations expand the social domain of individuals acquainted with register stereotypes, and allow individuals, once aware of them, to respond to their characterological value in various ways, aligning their own self-images with them in some cases, transforming them in others through their own metasemiotic work (Agha 2003:242).

His point therefore is that metapragmatic representations provide evidence that accounts for how linguistic variables, such as the features of an accent like RP, come to function as a resource for the making of meaning and the indexing of social identity. However he also highlights the ideological nature of this process and the extent to which such meanings are created, sustained and challenged through on-going acts of evaluation.

The relevance of Agha's work to the concerns of this paper, the evaluation of swearword use, is that it has the potential to generate a different set of research questions, and a different focus, to those of the studies discussed in Section 2 above, and as such this approach has the potential to add a layer of explanation to the findings of those studies. 
Such an analysis would begin with a search for evidence of regularity in the range of social meanings generated by the use of swearwords by analysing the metadiscourses that recur across different types of situated cultural text. Agha's account would predict that such evidence would be found in metapragmatic comments on swearing that occur in the media, in the use and responses to swearing that are in cultural texts such as television soaps, novels, etc., as well as in the evaluations evident in everyday interaction. However, significantly, this approach would not predict that interlocutors will have equal access to either the metadiscourses or the values generated by these metadiscourses, or have the same relationship with them. As (Agha, 2003:242) points out, interlocutors may align their own self-images with these social meanings or transform them through their own metasemiotic work.

Agha's approach predicts that evidence of a conventionalised understanding of the significance of formulae such as swearwords, as well as of alternative understandings, is likely to be found in the systematic study of the metadiscourses of swearword use. This is an important step in building up a picture of the processes involved in individual and shared evaluations of swearword use. How these understandings are generated in the first place is highly relevant however since, as Agha points out, these are ideologically charged. That issue is addressed by Silverstein's (2003) notion of the 'indexical order', which I briefly outline below.

\subsection{The indexical order (Silverstein, 2003)}

Silverstein claims that the notion of an 'indexical order' is necessary if we are "to relate the micro-social to the macro-social frames of analysis of any sociolinguistic phenomenon" (2003:193). He describes the relationship between Agha's notion of a register and indexical orders as follows: 
The existence of registers ....is an aspect of the dialectical process of indexical order, in which the $n+1$ st-order indexicality depends on the existence of a cultural schema of enregisterment of forms perceived to be involved in $n$-th order indexical meaningfulness; the forms as they are swept up in the $n+1$ st order valorization become strongly presupposing indexes of that enregistered order, and therefore in particular of the ideological ethno-metapragmatics that constitutes it and endows its shibboleths with $n+1$ st-order indexical value. (193)

Silverstein's points here are probably best understood by drawing on Eckert's (2008) application of his insights in her reassessment of Labov's distinction between indicators, markers and stereotypes. Eckert points out that Labov's conceptualisation of an indicator is what Silverstein would categorise as a $1^{\text {st }}$ order index:

A first-order index simply indexes membership in a population - it designates people as Martha's Vineyarders, Beijingers, Detroiters. In the case of Labov's (1966) New York City study, which Silverstein uses as his example, the populations may be social class strata (Eckert, 2008:463).

An $n+1^{\text {st }}$ order index would be a variable that has, in Labov's terms, become a marker in that it is a linguistic variant whose use correlates with variation in style. As Eckert, following Silverstein, points out: a form that has acquired an indexical value can always be reinterpreted so that it acquires "an $n+1^{\text {st }}$ value" (2008:463). However, an $\mathrm{N}+1^{\text {st }}$ order index has a different significance to the notion of a marker in variationist sociolinguistics in that, within an indexical approach, it leads to a focus on the process of meaning making:

The difference between the notion of marker as used in variation studies and the index of Silverstein's treatment is in the ideological embedding of the process by which the link between form and meaning is made and remade. Participation in discourse involves a continual interpretation of forms in context, an in-the-moment assigning of indexical values to linguistic forms (Eckert, 2008:463). 
As Eckert points out, what Silverstein's notion of an indexical order brings to variationist sociolinguistics (via Agha's notion of enregisterment) is an account of how variants come to be linked with specific social meanings, and how this linking is an active, on-going process: it is through repeated acts of social evaluation carried out by "socially locatable persons" (Agha, 2003:242) that makes it possible for a variant to index a specific range of social meanings. This process is explained by Eckert's development of the notion of the indexical field.

\subsection{The Indexical Field (Eckert 2008)}

Eckert articulates the significance of approaching sociolinguistic variation from an indexical perspective by showing how, although there is evidence in early variationist studies that the meanings attached to variants are ideologically motivated, this evidence is not fully recognised or developed in these accounts. She argues, for example, that Labov interpreted the correlation between the centralization of /ay/ and certain categories of people in Martha's Vineyard, as evidence that the meaning of the variation is a local construction: in this case it signalled resistance to mainland incursion. However, as she goes on to argue, such local meanings were not actually addressed by Labov, or by subsequent variationist sociolinguists. For example although, as Eckert points out, Trudgill argued that it was the "perceived toughness of working-class men" that explained language change in that it led to middle-class men adopting regional working-class variants, she goes to argue that this account does not address the process by which "meanings become associated with social categories or with variables" (Eckert, 2008:455).

Following Silverstein (2003), Eckert reinterprets the findings of large-scale social surveys from this perspective, showing the significance of explaining the correlational data of such surveys as indexical. Starting from the premise that once an association has been 
made between a social group (for example, a specific class of people in New York) and a form used by that group (for example, post-vocalic $/ r$ ) that form is available to be used indexically (e.g. by a worker in a New York store to indicate something about social status). Her argument is that the goal of sociolinguistics today should be to explain how variants function by focusing on the ideological field that generates the indexical potential of variants. She describes this field as a product of "the continual reconstrual of the indexical value of a variable" (Eckert, 2008:463-4). Her point is also that whenever a linguistic resource is used, it has the potential to change that field.

The field is fluid, and each new activation has the potential to change the field by building on ideological connections. Thus variation constitutes an indexical system that embeds ideology in language and that is in turn part and parcel of the construction of ideology. (453)

\section{TOWARDS A DISCURSIVE PRAGMATIC APPROACH TO THE INDEXICAL VALUE OF STRONG SWEARWORDS}

Although the indexical approach I have discussed so far provides a framework for exploring the scope of the indexical field, I would argue that currently it is, essentially, a sociolinguistic rather than a pragmatic approach: it does not describe or explain how, within a specific linguistic interaction, the use of a specific resource comes to index a specific stance, a specific act, or a specific aspect of social identity. The approach might give access to the meanings a linguistic form can generate, but it does not describe or explain the meaningmaking process itself, or how situated uses can generate specific meanings. As Wilson (2006:1723) observes: if a meaning is pragmatically inferred, "we need an account of how the inference is triggered, what form it takes and what types of outputs it yields". 
Blakemore (2011a:120-1) argues that the conceptualisation of both explicatures and implicatures as inferences, as it is set out in Sperber and Wilson's (1986) relevance theory, "does not correspond to any other distinctions that have been made in pragmatics." She points out that only relevance theory holds that the identification of contextual assumptions and conclusions, as well as explicitly communicated propositions, is governed by the same pragmatic principle. In a more recent work, Sperber and Wilson build on this view of the inferential nature of explicatures, drawing on research that has "cast doubt on the view that word meanings can be analysed in terms of context-independent prototypes, and suggests instead that ad hoc meanings are constructed in context" (Sperber and Wilson, 2011:157). In particular the following claims about the nature of linguistic encoding inform my analysis:

[T] he occurrence of a word in an utterance provides a piece of evidence, a pointer to a concept involved in the speaker's meaning. It may so happen that the intended concept is the very one encoded by the word, which is therefore used in its strictly literal sense. However, we would argue that this is no more than a possibility, not a preferred or default interpretation. Any interpretation, whether literal or not results from mutual adjustment of the explicit and implicit content of the utterance. This adjustment process stabilises when the hypothesised implicit content is warranted by the hypothesised explicit content together with the context, and when the overall interpretation is warranted by (the particular instantiation of) the communicative principle of relevance.

Following Sperber and Wilson (1986); Wilson and Sperber (2004), Carston (2009) and Sperber and Wilson (2011) my analysis is predicated on the following axioms:

I. The identification of the explicit content of an utterance is as inferential a process as the recovery of implicatures.

II. Context does not precede an utterance, but is a function of utterance interpretation. The context of an utterance is a set of assumptions assigned by the hearer in the process of interpreting an utterance. The context of an utterance from this perspective 
is the specific set of assumptions that a hearer or reader activates when generating the most relevant interpretation (to her) of the particular linguistic forms, intonations patterns, etc. that constitute the utterance.

III. The range of meanings that a specific use of a strong swearword is assigned will have been derived from the pool of assumptions that make up the individual cognitive environments of individual interlocutors. However, I do not assume that the cognitive environment of one interlocutor will overlap with that of another.

In what follows my aim is to show that an approach that links relevance theory to the sociolinguistic theorisation of indexicality can help to explain the generation of specific social meanings ascribed to specific uses of swearwords. I begin with evidence of the 1st order indexing potential of strong swearwords, then consider evidence that these forms have been 'swept up in the $\mathrm{N}+1$ st order valorization' process by which they become 'strongly presupposing indexes of that enregistered order' (Silverstein, 2003:193). I then use newspaper reports to show that regularities in the register values assigned to swearword use are evident in examples of situated metapragmatic commentary. Finally, I show how these ideologically related meanings are activated in evaluations of specific uses of swearwords.

\subsection{Strong swearwords as a first order index.}

McEnery and Xiao's (2004) analysis of the British National Corpora is an example of a large scale survey that provides evidence of correlations between social groups and the use of swearwords. Here I summarise just those aspects of their findings that indicate a relationship between gender, class and the use of fuck as these illustrate patterns of behaviour that would suggest that the use of the word is associated with a specific population and therefore that it functions as a 1st order index. The tables below are adapted 
from the McEnery and Xiao's (2004:242-4) findings to show the net result of uses of fuck, fucked, fucks, fucking and fucker according the speaker gender, and a cross tabulation which incorporates the data for gender and for class (RF is the raw frequency and NF is the normalised frequency).

Table $1 \quad$ Use of all forms of the word fuck by speaker gender

\begin{tabular}{|c|c|c|c|c|}
\hline Gender & Words & RF & NF & Sig. level \\
\hline Male & $4,918,075$ & 1779 & 361.73 & $<0.001$ \\
\hline Female & $3,255,533$ & 444 & 136.38 & \\
\hline
\end{tabular}

The authors observe that when all word forms are taken as a whole, male speakers use fuck more than twice as often as female speakers, which is statistically significant. However, as the authors point out, when the results were broken down to take into account variation in the use of specific forms, they point even more strongly to a predominantly male use of fuck as a swearword. They argue, for example that frequencies of male and female speakers' use of the specific words fucked and fucks is not significant, and that this might be because these two word forms can denote the 'literal' meaning of the word. When word forms were analysed individually they found that the variation between male and female speakers' use of the word fucking (for which the normalised frequency is Male: 283.44 and Female: 98.6 ) is even more strongly suggestive of a predominantly male use than the above figures indicate.

The table below indicates that variation between male and female use of fuck is evident across all four classes, and also indicates that its use correlates strongly with the population 'working class males'.

Table 2: Use of the word fuck. cross-tabulation of speaker gender and social class

\begin{tabular}{|c|c|c|c|c|c|}
\hline Class & Gender & Words & RF & NF & Sig. level \\
\hline AB & Male & 266,857 & 175 & 655.78 & $<0.001$ \\
\hline & Female & 413,150 & 127 & 307.39 & \\
\hline
\end{tabular}




\begin{tabular}{|c|c|c|c|c|c|}
\hline C1 & Male & 187,946 & 43 & 228.79 & $<0.001$ \\
\hline & Female & 239,926 & 3 & 12.5 & \\
\hline C2 & Male & 169,737 & 348 & 2050.23 & $<0.001$ \\
\hline & Female & 315,945 & 9 & 28.49 & \\
\hline DE & Male & 126,512 & 176 & 1391.17 & $<0.001$ \\
\hline & Female & 138,247 & 84 & 607.61 & \\
\hline
\end{tabular}

As McEnery (2006: 5) points out "While corpus data allows us to describe swearing in English, for example, it does not begin to provide an explanation for anything that we see within the corpus". However, even though this is only one set of data, and it can only indicate tendencies, it does provide preliminary evidence that, at a particular moment in British culture, the word fuck is most likely to be used by a specific population: working class males (although the results for the $A B$ and $D E$ class raise some interesting questions that are worth investigating further).

The sociolinguistic approach to indexicality proposes that "variables index demographic categories not directly but indirectly, through their association with qualities and stances that enter into the construction of categories" (Eckert, 2008:455). The correlation between population and word-use would suggest that the word fuck has the potential to be transformed from a 1st order index (strong swear words $\rightarrow$ working class males) so that it acquires an $n+1$ st value. On the basis of folk-linguistic knowledge as well as sociological evidence, the link between the population 'working class males' and the use of vernacular forms, including swearwords, has clearly been subject to such a process for some time. But observing that such a correlation exists tells us nothing about how it is that "meanings become associated with social categories or with variables" (Eckert, 2008:455). And without an engagement with those processes there can be no explanation for how such associations come and go, or how they change over time. It also cannot tell us anything about whether all members of a society make those associations, or just some members. 
Before considering how these processes might be addressed, it is worth setting out evidence from empirical studies of language-use that suggests the scope of the indexical field of strong swearwords.

Stapleton's (2010) consideration of the interpersonal function of swearwords provides a useful overview of the cultural values that have been ascribed to the use of strong swearwords, and shows that these ascriptions draw on (and perpetuate) stereotypes of the population 'working class males'. In her report she surveys studies that chart a perceived link between socio-economic class and swearing and these offer some evidence of the enregistered order that might be indexed by swearword use. She observes that: in most languages, swearing is strongly linked to the vernacular, thereby carrying connotations of "working class culture" and lower socioeconomic groupings [...]. In terms of social judgments, this means that the use of expletives is often associated with lower levels of education and/or socioeconomic standing; as reflective of standard versus non-standard language use (2010:291)

Stapleton goes on to argue that, "Because of its associations with both aggression and vernacular/slang, swearing has traditionally been seen as the preserve of male speakers" (293). Her account shows therefore that a specific set of ideological connections is clearly in play when swearword use is evaluated. The studies she surveys show that informants are linking swearing with aggressive behaviour and vernacular use, and also linking all three behaviours with a specific population: working class males.

Interpreting Stapleton's survey data from an indexical perspective therefore, it can be seen as evidence that these forms have been re-interpreted so that they acquire an " $n+1$ st value" (Eckert, 2008:463) process. From Silverstein's perspective this would predict that when strong swearwords are used by a population other than that presupposed by the 1st order index, they will be subject to an on-going set of cultural evaluations based on register 
stereotyping, which is to say that these specific forms of taboo language will have become "strongly presupposing indexes of that enregistered order" (Silverstein, 2003:193). There is evidence that upholds this prediction in Stapleton's survey. She points out, for example, that “the 'popular myth' surrounding linguistic taboo [...] means that swearing inevitably acquires different meanings, and therefore functions differently, for male and female users" (2010:293). Even though, as she observes, some studies have shown that there are actually "few gender differences in overall knowledge and usage" of swearwords (2010:293), there is still evidence that men's and women's use of strong swearwords is judged in the context of masculine stereotyping, and as a result women's use of swearwords is perceived as inappropriate.

Stapleton's findings on swearword use are consistent with variationist explanations of gender and language-use that have been proposed in the past, where men's language-use has been accounted for by an assumed orientation towards covert prestige values. However, as Eckert (2008:455) points out, such explanations are "vague about the nature of the connection between toughness, gender, and class". Stapleton's survey of studies provides plenty of evidence that the connection exists and, importantly, also indicates that this connection is reproduced through the acts of evaluation carried out by the informants of the studies. In the next section, I analyse one set of cultural texts in order to show how they display evaluations of swearword use that make explicit the ideological bases of this connection, and potentially keep that connection active.

\subsection{The indexical field of strong swearwords in British news reports.}

In what follows I report on an analysis of a corpus of newspaper reports made available by the database Nexis which shows that the use of strong swearwords is regularly rationalised in ways that explicitly link affective stances, social roles and group identities to the register 
stereotyping discussed above. In searches over the period of March 2011 to February 2012 of newspaper reports where the lexeme swear features in the headline or the by-line, a preliminary analysis has brought to light two types of news report that evaluate swearing. Firstly, there are reports that comment in some way on swearing as behaviour, where the focus is not on actual instances of swearword use. Examples of this type are reports that discuss advice given to police officers not to arrest people for swearing ("Swearing at the police is no crime, rules judge.” The Daily Telegraph 21st November 2011). Other examples of this first type are where an incident of swearing has led to a general discussion of when or if it is appropriate to swear ("Radio clampdown on bad language to protect children." Daily Mail 21st December 2011). Although this first type of report yields interesting results, there is space here only to focus on some examples of a second type of news report: those which comment on specific incidents where swearwords have been used. I focus on this type of report in order to show how evaluations of swearword use are supported by rationalisations that draw on underlying assumptions about when the use of strong swearwords is and is not acceptable.

The reports are situated texts (in Agha's terms): the evaluations take place within the newspaper setting and therefore are a product of the genre which would include, for example a specific agenda: the goal of such a report might be to sensationalise an act or raise public concern about an issue in order to engage as wide a readership as possible and therefore sell more newspapers. And since the reports are designed for a mass readership, any evaluation has to be rationalised by drawing on relatively uncontroversial perceptions of swearword use if it is to be meaningful to that readership. From a relevance-theoretical perspective, then, the reports assume (but cannot guarantee) that the author and potential readers have a 'mutual cognitive environment', in the sense that key assumptions that are 
accessible to one are accessible to the other. More importantly, however, these assumptions are the starting point, not the end-point of the communication process. As Blakemore (2011b:3541) has argued, "communication is not geared towards the duplication of thoughts, but rather to what Sperber and Wilson describe as the enlargement of mutual cognitive environments. iii"

My claim is that since, from a relevance-theoretical perspective, context is a function of an utterance, the evaluations of swearwords in newspaper reports provide evidence of two sets of assumptions: (a) the mutually manifest contextual assumptions about general swearword use that the evaluations require a reader to generate if she is to be able to interpret the propositions she assigns to the report as relevant (and which assumptions provide indirect evidence of the mutual cognitive environment of the writer and the assumed reader); and (b) the implicatures generated by evaluations of specific uses of swearwords in the reports: the specific implicated premises (contextual assumptions) supplied by the reader that enable the reader to infer the implicated conclusions (contextual implications) communicated by the writer when evaluation specific acts of swearing.

My point is that although the reports appeal to (and provide evidence of) shared assumptions about swearword use, it is the subset of those assumptions, activated in the process of generating a relevant interpretation of a report, that explains context-specific interpretations of swearwords. To illustrate my point, in what follows I focus on just two incidents of swearing and one 'implied' use of a swearword that occurred in 2011. The first was an incident in which the British football player Wayne Rooney ran up to a television camera after he had scored a goal and shouted "You fucking beauty" into it. This incident resulted in a hearing at which the Football Association (FA) banned the player for two matches. The actions of the FA as well as Rooney's behaviour were the subject of a great 
deal of debate in the British press in the subsequent weeks. The second is an incident when the actor Gwyneth Paltrow said on an American television show that her grandmother was "a real cunt". This incident was also subject to some limited debate in the British press. The third is an incident on a BBC radio programme, The News Quiz, in which the compere, Sandi Toksvig, said: "It's the Tories who have put the "n" into cuts."

I begin with an indication of the indexical field of the use of strong swearwords where the metapragmatic commentary constructs their use as normal in certain circumstances. In particular I show that there is a metadiscourse of swearing that legitimises one social group's use of swearwords when that swearing takes place within certain parameters of use. I also show that in instances of swearing that do not map onto these parameters, this same metadiscourse is used to evaluate uses of swearwords negatively. However, what these evaluations also show is that these uses of swearwords are likely to have been evaluated quite differently by other social groups, and would suggest that there are other, conflicting, metadiscourses of swearing that exist alongside those informed by the dominant ideology evident here, and which would repay further investigation.

\subsubsection{Evidence of a metadiscourse that normalises swearword use}

Each of the reports discussed in this section is triggered by Rooney's specific act of swearing at the camera. There are many more implications to be drawn from an analysis of these reports, here I have limited my account to show that each refers to swearing in general terms and each, in invoking a set of contextual assumptions (CAs) for interpreting the use of swearwords generates contextual implications (Cls) that normalise occurrences of swearing by football players during football matches. What is particularly interesting here is that these Cls are generated by different sets of CAs. 
This contextual implication generated by the italicised element of the following report illustrates this:

We hired expert lip readers to scan live games and highlights on TV for players using obscene language. Newcastle skipper Joey Barton told the ref, the opposition and even his own players to "f*** off", while Wolves boss Mick McCarthy was spotted telling one of his players to "f*****$g$ stay there". [....] Former team-mate Gary Neville defended him [Rooney], saying: "If swearing is a crime worthy of a two-game ban, there will be nobody left on the pitch." [my italics] (Foul! Wayne Rooney isn't the only one swearing for the camera as one weekend of TV football shows. The Mirror April 12, 2011)

The pragmatically generated explicatures of the italicised element here require some degree of narrowing. For example, nobody must be narrowed to signify 'no footballers' and on the pitch must be narrowed to signify 'on the football field during a game of football'. If the explicatures of the italicised element of Neville's utterance are something like: "if swearing on the football pitch is banned there will be no footballers available to play in matches" then interpreted in conjunction with the CA: "football matches can't be played unless footballers are on the pitch" then the $\mathrm{Cl}$ would be something like: "If football matches are to be played then footballers must be allowed to swear". What makes this interpretation relevant in the context of the propositions expressed in the remainder of the article is that it justifies the use of swearing on the pitch: if, given the evidence that football players swear on the pitch, swearing was to incur a ban, then all players will be banned. For football to continue, then swearing in games of football must continue.

The second report also generates a $\mathrm{Cl}$ that normalises swearing on the football pitch, but in this case, this interpretation is generated by an assumed link between the football field with the workplace, and this link accounts for the FA's previous lack of reaction to Rooney's swearing. 
In May 2005, in one match with Arsenal alone, he [Rooney] was caught swearing at referee Graham Poll at least 20 times. The FA did not act, despite the incident being highlighted, because they understand the football field to be a workplace and industrial language part of its currency [my italics]. (Time for United's Moral Minority to move on. Daily Mail April 27, 2011)

If the propositions expressed by the italicised part of the final sentence here are to be read as an explanation of the FA's lack of action, the reader needs to supply a set of implicated premises which together with the explicatures of the utterance generate the implicated conclusion: "swearing is to be expected on the football field". Specifically, these CAs include the presuppositions that:

(a) the football field is a workplace setting (b) swearing always occurs in workplace settings.

For these premises to be interpreted as relevant CAs, the explicitly communicated element must be pragmatically modified so that the term workplace is narrowed to signify 'industrial workplaces', and the 'loose use' (Wilson and Sperber, 2007) of the item industrial language is narrowed to signify 'swearing'. The Cl "swearing is to be expected on the football field" can therefore be justified in the following terms: if the football field is an industrial workplace and swearing always occurs in industrial workplaces, then swearing will occur on the football field. What makes this a relevant interpretation of the italicised elements in the context of the remainder of the article is that it explains why the FA had not responded to Rooney's previous swearword use. The evaluation of swearing in this report then is that swearing is unremarkable in certain circumstances. I would also argue that, in British culture, working out what those circumstances are requires the reader to be able to link a particular type of workplace to the use of swearing: i.e. industrial rather than, say, office workplaces; and to link this to working class rather than middle class work. 
A third report that also rationalises swearing as normal in football matches does so through linking swearing with emotion:

"It happens 20 times every match. I can't understand why this [Rooney's swearing] is different. You can't take emotion out of football." [my italics] (What they @!"\$@*! said about Roo's ban. Sun April 9, 2011)

For the proposition expressed by the final sentence to be interpreted as relevant, the reader has to pragmatically generate a set of explicatures that involve the narrowing of the word emotion to signify 'swearing'. If the explicatures are taken to be:

(a) emotion [in the sense of swearing] is an intrinsic part of playing football

And if the contextual implication that derives from the co-text functions here as a relevant contextual assumption:

(b) Rooney swears twenty times in every match

then the contextual implication generated by the synthesis of $(a)$ and $(b)$ is that

(c) There is no reason to see the Rooney's current swearing as exceptional.

These reports would suggest that the pragmatically generated indexical field of strong swearwords is that their use potentially indexes social roles such as football player and industrial worker, aspects of social identity such as belonging to the groups 'men' and 'working-class', and potentially indexes an 'emotive' affective stance. In what follows I show that this same indexical field informs reports that explicitly evaluate Rooney's utterance "You fucking beauty".

\subsubsection{Uses of the normalisation of swearing metadiscourse to rationalise negative evaluations of Rooney's swearing.}


The extracts I discuss in this section illustrate how the CAs identified above are activated in generating relevant interpretations of reports that evaluate Rooney's act of swearing as a misjudgement on his part. The following extract implies this through the list of inappropriate contexts for swearing it offers:

Spurs boss Harry Redknapp said: "I wouldn't expect my players to run up to a camera and swear no more than I would have to tell them 'Don't mug an old lady on the way home'.

"Why do you have to go up and swear into the camera when there's kids watching? We don't need it.

"It depends what your morals are. Some people swear in front of women which I don't understand." (Ferguson ramps up FA feud to keep United on the boil; Scot creates siege mentality at Old Trafford by claiming governing body pressurised referee over Rooney rant. Sun April 9, 2011)

The references to mugging and not swearing in front of children and women here are relevant if the reader supplies the CAs:

(a) old ladies should not be mugged

(b) children and women should not be exposed to swearing

This evaluation of Rooney's swearing draws on the indexical field of swearword use set out above. The acceptability of swearing in an adult, male environment is implied by its contrast with the list of proscribed behaviour: it is not swearing itself that is proscribed, it is doing so in the wrong environment. There is a further ideological link being generated here:

Redknapp's evaluation draws on and perpetuates a register stereotype of a type of man whose lack of morals is evident through their treatment of women: whether it is mugging them or swearing in front of them (and indeed to interpret his utterance as meaningful, these two acts need to be seen as equivalent in some way). And Redknapp's professed inability 
to understand such behaviour constructs a persona for himself as someone who would not behave towards women in this way.

This view that Rooney's swearing is an act of misjudgement is also evident in the following quotation from a former referee:

"But you wouldn't swear in the face of your parents like that, you wouldn't do it in church and you wouldn't let off steam like that in the middle of a crowded supermarket, so why should you get away with it at a football match which is being shown all over the world live on TV?" (Ref Rage: FA put Rooney official under unfair pressure claim colleagues. The Mirror April 8, 2011)

Here the implicated premises include the CA: "swearing in front of one's parents or in a church is not acceptable". The reader also has to make a link between swearing and emotion. For the proposition in the second italicised clause to be perceived as relevant, the phrase let off steam, which has the potential to signify 'express emotion' through a range of forms, has to be narrowed here to signify 'express emotion through swearing'. Also the term crowded supermarket has to be broadened to signify 'in public'. These pragmatic inferences about the explicit meaning of these clauses are necessary if the causal connection implied by the word so is to be justified here. The interpretation here is that if

(a) in a public place, it is wrong to express strong emotion through swearing and

(b) a televised football match is a public space then

(c) it is unacceptable to express strong emotion through swearing in a televised football match.

Note again that the act is condemned because it is seen as a misjudgement about where swearing should occur rather than because swearing itself is to be condemned. Note also that the writer here is, in listing proscribed behaviour and raising questions about Rooney's 
expectations, also constructing his persona in opposition to that of a man who swears in the wrong context and is unable to control the expression of emotion.

The metadiscursive construction of swearing as an expression of emotion is also employed in the following example which again evaluates Rooney's behaviour as misguided: What his swearing did have, though, was a deep, deep, painful anger. Which is, I guess, why even I was taken aback. Swearing is normally just swearing. But Rooney's swearing was something else. It wasn't Rooney's words that counted, it was the thought behind them. It was about what he thinks we think of him. And that thought was thick with violence and anger and hatred. He opened not just his mouth but his heart to us. And that, we learnt, was not a nice place to be. (What the...? Sport loses its way in a four-letter moral maze. The Independent April 6, 2011)

Rooney's swearing is evaluated as misguided here on the grounds that it constitutes an uncontrolled exposure of deeply felt emotions. The reader needs to activate the CA

(a) the public display of "deep painful anger" is inappropriate

if she is to interpret the clause "even I was taken aback" as relevant. Again, the writer here is indexing his own stance as someone who can see swearing as "just swearing" in some contexts, but he constructs this incident as the behaviour of a man who is unable to control his emotions, and therefore is doing more than "just swearing".

The link between swearing and emotion is also invoked in this final example:

What made Rooney's behaviour all the more puzzling was the fact that, at the end of a troubled year on and off the pitch, he had just completed a fantastic hat-trick to haul his team back from the brink of a defeat that would have damaged their title hopes. 'Why do some of these young players have to be so angry with the world?' asked Tottenham boss Harry Redknapp last night. 'They're getting hundreds of thousands of pounds to play.' There are no easy answers. (First it was Fergie, now they are tackling his biggest star. Daily Mail April 5, 2011) 
In his evaluation of Rooney's swearing, Redknapp refers to the amount of money footballers such as Rooney are paid. If the reader generates the implicated premise that 'people who are paid a lot of money have no right to be angry at the world' she is able to draw the $\mathrm{Cl}$ that Rooney as no right to be angry at the world. However, the CA that swearing is a reflex of a strong emotion such as anger is treated as mutually manifest and as not requiring an explicit rationalisation. The point here is that if Rooney's anger cannot be justified then his swearing cannot be justified.

\subsubsection{Uses of the normalisation of swearing metadiscourse to rationalise negative evaluations of Paltrow's and Toksvig's swearing}

The following are reports in British newspapers of Gwyneth Paltrow's use of the word cunt on an American television chat show, and Sandi Toksvig's implied use of the word in a British radio programme. The aim here is to show that where the metadiscourse is employed in these instances, it draws on a slightly different, but connected, set of CAs.

When Paltrow swears, she and the host of the show she is appearing on are discussing their dislike of their respective grandmothers, and Paltrow's response follows the host's comment that her own grandmother "was a bitch." Both women are laughing during the talk, as are the audience.

I propose, in what follows, that the reports in the British press generate the $\mathrm{Cl}$ that Paltrow's use of the word cunt lacks 'authenticity'. The first report cited here evaluates the swearword use as designed to shock the audience for the sake of self-promotion.

And there seemed to be something curiously staged about the incident. Was Paltrow just trying to be edgy and cool on late-night television? Or - even worse did she swear merely to grab attention and help promote her new cookbook. (Gwynnie, I swear you're an old phoney. Mail Online April 30th 2011) 
Here the label phoney implies that whatever social identity Paltrow is attempting to index through her swearword use here, it has not been successfully indexed, and this failure is down to the lack of authenticity in her swearword use. The use of the word 'staged' is relevant only if a reader is able to interpret the pragmatically inferred explicature:

(a) Paltrow's use of the swearword was not spontaneous

in the context of the implicated premise that:

(b) Uses of swearwords that are not spontaneous are inappropriate

and is therefore able to generate the $\mathrm{Cl}$ :

(c) Paltrow's use of the swearword is inappropriate

In the indexical field mapped out above, the use of strong swearwords is to be expected when speakers respond to emotion or where it is justified by an aspect of social identity: i.e. if the speaker is male and working class. If this is the measure of appropriate swearword use in the metadiscourse, then Paltrow's swearword use is not appropriate.

Moreover, in the above report, and a second report cited below, it is implied that the reason Paltrow's use of the word was unacceptable was because it was designed to index an aspect of social identity that she was not entitled to index. In the above report the features of that identity are named as edgy and cool, in the report below as a bad girl.

WHO does Gwyneth Paltrow think she is? Seems like she doesn't know any longer... She can't pretend this slipped out accidentally like Janet Jackson's wardrobe malfunction. Any seasoned performer who uses this kind of language on TV does it on purpose. Gwynnie's been Hollywood's goody-two-shoes for so long and she's trying very hard to be a bad girl. Trying too hard I reckon. (Hollywood trucker girl. The Express April 30th, 2011) 
In this second report, the claim that Paltrow's behaviour can't be explained as an accident implies that an accidental use of taboo language might be acceptable. What makes her behaviour unacceptable therefore is that it is, again, because it is intentional. It cannot be explained away as a spontaneous emotional reaction, or simply the expression of her identity as a 'bad girl'.

One final example of a negative evaluation of swearing that derives from the employment of the metadiscourse is particularly interesting in that it brings together a number of the CAs identified above. On a BBC programme, The News Quiz, Sandi Toksvig cited the line: "It's the Tories who have put the "n" into cuts." Even though in this instance a swearword was not actually used, but implied, the occurrence still led to a debate in the press and a call by MPs to have the standards of the BBC investigated since the programme was broadcast at a time when children might have heard it. The BBC defended the programme, saying the swear word 'had lost much of its 'shock value'" (Daily Telegraph 6th June 2011, p.7). A commentator who took issue with this defence by the BBC evaluated the use of swear words as follows:

It is simply not true to declare that the expletive has lost its shock value. It is a term of abuse. And - witty or not - Sandi was deliberately invoking it to abuse the Conservative Party, in that leery, sniggering, News Quiz style [....] A broadcaster making a slip of the tongue [...] is one thing, but to choose to allow the taboo to be broken (even if obliquely) in a pre-recorded programme, and then defend the decision by saying that times have changed . . . it's disingenuous, devious and dishonest. (Prime-time smut, vile obscenities on Radio 4 and a smug elite who sneer at the silent majority. Mail Online June $6^{\text {th }}$ 2011)

Again, the $\mathrm{Cl}$ here is that artful, insincere uses of swearwords are not acceptable uses. To interpret the first italicised elements of the report here as relevant, it is necessary to generate the implicated premise that uses of swearwords are acceptable only if they are the 
spontaneous expression of a particular type of identity, and that to pretend otherwise is "disingenuous, devious and dishonest". And moreover the type of identity that might be indexed through the use of strong swearwords is certainly not the 'smug elite' that is referred to in the second italicised element, which is the title of the piece.

The evaluations of the use of cunt by Paltrow, and the implied use of the word by Toksvig are clearly drawing on the metadiscourses outlined above, in which swearing under certain circumstances is acceptable: the criticisms presuppose the truth of the propositions that form that metadiscourse. These instances are therefore not legitimised in the activities of the 'socially locatable persons' whose views are promulgated in the specific sections of the national press I have cited here. The evaluations nicely illustrate Agha's argument that the metapragmatic activity evident in cultural texts draws on and perpetuates 'metapragmatic stereotypes' which he argues are "identifiable for a particular social domain of evaluators, e.g. a particular sub-population within a society" (242). However, as I indicated above, Agha also argues that metapragmatic evaluations, because they are ideological, will be not be consistent across a given society. This would predict that there are likely to be alternative metadiscourses of swearing that are not being activated in the sorts of media text I have cited. I would argue, in particular that there is a metadiscourse of women's legitimate uses of swearwords that is still to be mapped, both within and beyond such texts, which would bring these inconsistencies into view. The fact that Toksvig and Paltrow used or implied the use of a swearword that is perceived as one of the strongest in British English would presuppose the existence of such a metadiscourse. And it would, in Agha's (2003: 242) terms, provide "evidence for the co-existence of distinct, socially positioned ideologies of language within a language community". 
This preliminary mapping of the indexical field of swearing even within this very limited context brings to light evidence of the ideology of swearing that informs and justifies specific evaluations of actual uses. There is a great deal still to be explored here about the ideological stances evident in the metadiscursive commentary that links the use of strong swearwords with affective stances such as anger or hatred, with roles such as 'football player' and 'industrial worker', and aspects of social identity, such as membership of the social groups 'male' and 'working class'. While these links have been claimed by previous scholarship, and while metapragmatic comments have been explored in previous scholarship, here it is based on evidence of "regularities of evaluative behaviour" (Agha, 2003:242) that charts the activation of these ideological connections in the justification of situated interpretations of a specific act of swearing.

Rooney is not condemned for swearing per se. The analysis shows that, within the identified metadiscourse, the use of strong swearwords is to be expected by a man in a specific work environment, and it is to be expected of someone experiencing strong emotions. Where Rooney's swearing is evaluated as unacceptable, it is because it is not hidden from people who, according to this metadiscourse, should be protected from being exposed to swearing, and because it indicates that he is not able to stop himself from publicly displaying strong emotions. This mapping also provides evidence of the ideologies that are activated when the uses of swearwords by groups other than working class males are evaluated. The normalisation of swearing as behaviour that is associated with the expression of emotion and with working class, male workplaces informs comments which were critical of Rooney, as well as those that evaluated his swearing as justified in some way, or else empathised with it. My analysis of Paltrow's use of the word cunt and Toksvig's 
implied use of the word suggest that these same associations are used to construct these uses as inappropriate. These reports imply that swearword use that is not justified within the terms of this metadiscourse is to some extent delegitimised. However, as Eckert argues, an indexical field is fluid, and "each new activation has the potential to change the field by building on ideological connections" (453). The existence of such a metadiscourse does not rule out the existence of others, and does not rule out the possibility that other metadiscourse are already in existence and have the potential to change the scope of the indexical field of strong swearwords..

In this paper I have argued that approaching linguistic formulae from an indexical perspective can generate a set of research questions that have the potential to open up the study of (im)politeness phenomena so that it is possible to address the range of meanings a resource might generate in a given culture at a given moment in time, without relying on assumptions about the shared 'core' meaning of that resource. My argument is that this approach allows the claim that the effects of swearwords are conventionalised (Culpeper, 2011: 127) to be explored in a more systematic way. It also allows the claim to be addressed discursively. In showing some of the regularities that come to light through a mapping of the indexical field of strong swearwords, I have shown that the evaluative behaviour evident in news reports can be used to explain the meanings ascribed to specific uses of taboo language. I have also argued that approaching these evaluations from a relevance-theoretical perspective, the process whereby indexical values are assigned to swearwords is brought into view.

There are clearly many more social meanings indexed by strong swearwords than those addressed by these newspaper texts. For example, there is a whole metadiscourse of women's use of swearwords that is still to be mapped, and which does not feature in the 
media texts that I have addressed. I believe that it is not accidental the two latter evaluations of swearword use by women were evaluated as inauthentic. But that is for another project. There are many questions about the indexing potential of strong swearwords, and how it relates to the location of different metadiscourses of swearing that have yet to be addressed.

\section{Reference List}

Agha, Asif, 2003. The Social Life of Cultural Value. Language \& Communication 23, 231273.

Allan, Keith, Burrdige, Kate, 2006. Forbidden Words: Taboo and the Censoring of Language. Cambridge University Press, Cambridge.

Anderson, Kate T., 2008. Justifying race talk: indexicality and the social construction of race and linguistic value. Journal of Linguistic Anthropology 18, 108-29.

Blakemore, Diane, 2011a. Relevance theory. In Grundy, P., Archer, D. (Eds.), The Pragmatics Reader. Routledge, London, pp. 119-128

Blakemore, Diane, 2011b. On the descriptive ineffability of expressive meaning. Journal of Pragmatics 43, 3537-3550

Brown, Penelope, Levinson, Stephen, 1987. Politeness. Some Universals in Language Usage. Cambridge University Press, Cambridge.

Carston, Robyn, 2009. The explicit/implicit distinction in pragmatics and the limits of explicit communication. International Review of Pragmatics, 1, 35-62.

Christie, Chris, 2005. Editorial. Journal of Politeness Research, 1 (1), 1-7.

Cole, Debbie, 2010. Enregistering diversity: adequation in Indonesian poetry performance. Journal of Linguistic Anthropology 20, 1-21.

Cooper, Burns, 2007. Taboo terms in a sexual abuse criminal trial. International Journal of Speech Language and the Law 14, 27-50.

Culpeper, Jonathan, 2011. Impoliteness: Using language to cause offence. Cambridge University Press, Cambridge. 
Culpeper, Jonathan, Bousfield, Derek, Wichmann, Anne, 2003. Impoliteness revisited: with special reference to dynamic and prosodic aspects. Journal of Pragmatics 34, 1545-79.

Daly, Nicola, Holmes, Janet, Newton, Jonathan, Stubbe, Maria, 2004. Expletives as solidarity signals in FTAs on the factory floor. Journal of Pragmatics 36, 945-964.

Dewaele, Jean-marc, 2010. The emotional force of swearwords and taboo words in the speech of multilinguals. Journal of Multilingual and Multicultural Development 25, 204-222. Eckert, Penelope, 2008. Variation and the indexical field. Journal of Sociolinguistics 12, 453476.

Eckert, Penelope, 2012. Three waves of variation study: the emergency of meaning in the study of sociolinguistic variation. Annual Review of Anthropology 41, 87-100 Hughes, Susan E., 1992. Expletives of Lower Working-Class Women. Language in Society 21, 291-303.

Jay, Timothy, Janschewitz, Kristin, 2008. The pragmatics of swearing. Journal of Politeness Research 4, 267-288.

Johnson, Danette Ifert, 2012. Swearing by peers in the work setting: expectancy violation valence, Perceptions of message, and perceptions of speaker. Communication Studies 63, 136-151.

McEnery, Tony. 2006. Swearing in English: Bad language, purity and power from 1586 to the present. Routledge, London.

McEnery, Tony, Xiao, Zhonghua, 2004. Swearing in modern British English: the case of fuck in the BNC. Language and Literature 13, 235-268.

Mail Online, 2011a http://www.dailymail.co.uk/debate/article-1381704/Gwyneth-I-swearyoure-old-phoney.html. Accessed 07/05/2013.

Mail Online, 2011b http://www.dailymail.co.uk/debate/article-1394679/BEL-MOONEYPrime-time-smut-vile-obscenities-Radio-4-smug-elite-sneer-silent-majority.html. Accessed 07/05/2013.

Millwood-Hargreave, Andrea, 2000. Delete Expletives? Research undertaken jointly by the Advertising Standards Authority, British Broadcasting Corporation, Broadcasting Standards Commission and the Independent Television Commission. ASA, BBC, BSC and ITC, London.

Ochs, Elinor, 1996. Linguistic resources for socializing humanity. In Gumperz, J., Levinson, S.

(Eds) Rethinking linguistic relativity. Cambridge University Press, Cambridge, pp. 407-438. Rogerson-Revell, Pamela, 2007. Humour in business: a double-edged sword: a study of humour and style shifting in intercultural business meetings. Journal of Pragmatics 39, 4-28. 
Silverstein, Michael, 2003. Indexical order and the dialectics of sociolinguistic life. Language \& Communication 23, 193-229

Silverstein, Michael, 2010. "Direct" and "indirect" communicative acts in semiotic perspective. Journal of Pragmatics 42, 337-353.

Silverstein, Michael, 2010. Society, polity, and language community An enlightenment trinity in anthropological perspective. Journal of Language and Politics 9, 339-363.

Snell, Julia, 2010. From sociolinguistic variation to socially strategic stylisation. Journal of Sociolinguistics 14, 630-656.

Sperber, Dan, Wilson, Deirdre, 1986. Relevance: Communication and Cognition. Blackwell, Oxford.

Sperber, Dan, Wilson, Deirdre, (2008) A deflationary account of metaphors. In Gibbs, R.W., (Ed.) The Cambridge Handbook of Metaphor and Thought. Cambridge University Press, Cambridge, pp. 84-105.

Sperber, Dan, Wilson, Deirdre, 2011. The mapping between the mental and the public lexicon. In Grundy, P., Archer, D. (Eds.), The Pragmatics Reader. Routledge, London, pp. 147-160.

Squires, Lauren, 2010. Enregistering internet language. Language in Society 39, 457-492. Stapleton, Karyn, 2010. Swearing. In Locher, M. Graham, S. L. (Eds), Interpersonal Pragmatics, Mouton de Gruyter, pp. 289-306.

Stenstrom, Anna-Brita, 2006. Taboo words in teenage talk: London and Madrid girls’ conversations compared. Spanish in Context 3, 115-138.

Stone, T. E., Mcmillan, M. Hazelton, M., 2010. Swearing: its prevalence in healthcare settings and impact on nursing practice. Journal of Psychiatric and Mental Health Nursing 17, 528-534.

Terkourafi, Marina, 2008. Towards a unified theory of politeness, impoliteness and rudeness. In: Bousfield, D., Locher, M. (Eds), Impoliteness in Language: Studies on its Interplay with Power in Theory and Practice. Mouton de Gruyter, Berlin, pp. 45-74.

Wilson, Deirdre, 2006. The pragmatics of verbal irony: echo or pretence? Lingua 116, 17221743

Wilson, Deirdre and Dan Sperber, 2004. Relevance theory. In Horn, L, Ward, G., (Eds.) Handbook of Pragmatics. Blackwell, Oxford, pp. 607-632.

Wilson, Deirdre, Sperber, Dan, (2007) On verbal irony. In Gibbs, R., Colston R., (Eds). Irony in Language and Thought: A Cognitive Science Reader. Lawrence Erlbaum Associates, New York, pp. 35-55. 


\footnotetext{
${ }^{\mathrm{i}}$ Eckert (2012, 87) describes this third wave approach as including the following tenets: (a) "the meanings of variables are underspecified, gaining more specific meanings in the context of styles" and (b) "variation does not simply reflect, but also constructs, social meaning and hence is a force in social change".

ii In the tradition of relevance theorists, I use he to refer to a communicator, and she to refer to the interpreter of an act of communication.

iii Blakemore (2011, 3541) glosses a cognitive environment as "the set of assumptions that an individual is capable of representing at any given time. A mutual cognitive environment is a cognitive environment which is shared by a group of individuals and in which it is manifest that they share it with each other.”
} 